\title{
Tuberculosis case-finding and treatment in the central prison of Qazvin province, Islamic Republic of Iran
}

\author{
M. Assefzadeh, ${ }^{1}$ R.Gh. Barghi ${ }^{1}$ and Sh.S. Shahidi ${ }^{1}$
}

$$
\begin{aligned}
& \text { كشف حالات السُل ومعالجتها في السجن المركزي في ولاية قزوين في جمهورية إيران الإسلامية }
\end{aligned}
$$

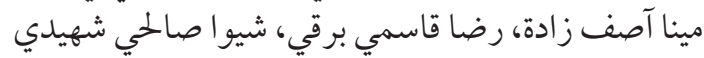

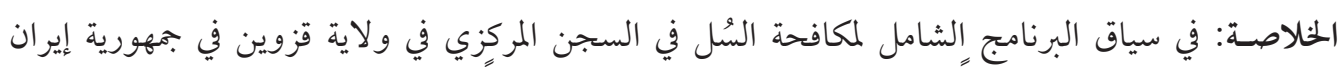

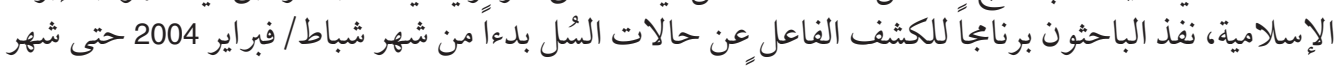

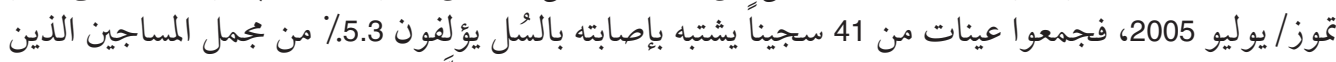

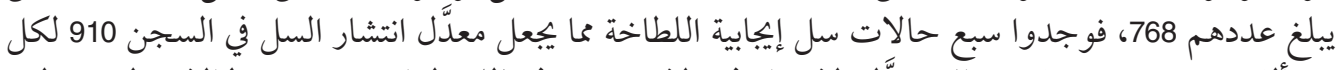

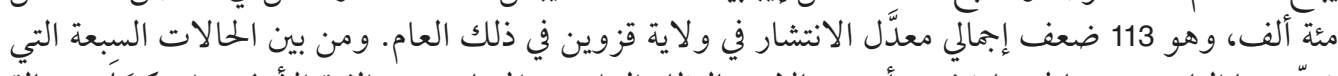

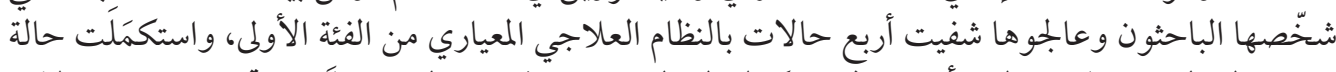

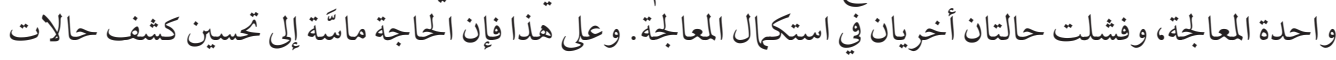

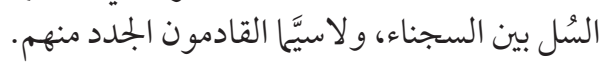

ABSTRACT As a part of a comprehensive programme of tuberculosis (TB) control in the central prison in Qazvin, Islamic Republic of Iran, a programme of active case-finding was carried out from February 2004 to July 2005. From the 768 prisoners examined, 41 (5.3\%) were suspected of TB and gave sputum samples. A total of 7 smear-positive TB cases were found, giving a TB prevalence in the prison of 910 per 100 000, 113 times the total TB prevalence in Qazvin province in the same year. From 7 diagnosed and treated patients, 4 were cured with the category 1 standard regimen, 1 completed treatment and 2 failed to complete treatment. Improvements are needed in TB case recognition of prisoners, especially newcomers.

Dépistage et traitement de la tuberculose à la prison centrale de la province de Qazvin (République islamique d'Iran)

RÉSUMÉ Dans le cadre d'un programme complet de lutte contre la tuberculose à la prison centrale de Qazvin (République islamique d'Iran), un programme de dépistage actif a été mené de février 2004 à juillet 2005. Parmi les 768 prisonniers examinés, on a recensé 41 (5,3\%) cas suspects de tuberculose, qui ont fourni des échantillons d'expectoration. Au total, sept cas de tuberculose à frottis positif ont été détectés, ce qui signifie une prévalence de la tuberculose dans la prison de 910 pour 100000 détenus, soit 113 fois la prévalence tuberculeuse totale dans la province de Qazvin au cours de la même année. Sur les sept sujets recensés et traités, quatre ont été guéris grâce au traitement standard de catégorie 1 , un a suivi le traitement jusqu'à la fin et deux ne l'ont pas terminé. II est nécessaire d'améliorer la détection des cas de tuberculose parmi les prisonniers, notamment les nouveaux arrivés.

\footnotetext{
${ }^{1}$ Department of Infectious Diseases, Qazvin University of Medical Sciences, Qazvin, Islamic Republic of Iran (Correspondence to M. Assefzadeh: mina_assefzadeh@yahoo.com).

Received: 07/05/06; accepted: 28/08/06
}

المجلة الصحية لشرق المتو سط، منظمة الصحة العالمية، المجلد الخامس عشر، العدد Y، 9 +. 


\section{Introduction}

The prevalence of tuberculosis (TB) among prisoners in all countries of the world is always higher than the general population [1], on average 100 times greater [2]. There are a number of factors that facilitate the spread of disease among prisoners [1,2]. First, there is a greater chance of being exposed to the TB bacilli and therefore becoming infected since the majority of prisoners come from low socioeconomic and deprived social classes, and are often homeless and/ or addicted to drugs and alcohol. Secondly, prisoners are more likely to suffer from poor immunity due to human immunodeficiency virus (HIV) infection, malnutrition, drug addiction and mental and physical stresses, resulting in reactivation of TB infection in this group. Thirdly, predisposing factors, such as overcrowding of the prison, long-term close contact with inmates and lack of access to adequate health services lead to undiagnosed or late diagnosis of TB. There is also likely to be poor compliance with TB treatment or incomplete treatment if prisoners are released before treatment has finished, encouraging the spread of multidrug-resistant TB.

There is a risk that the high TB prevalence in prisons can facilitate spread of the disease to the general population. However, with a regular programme of active casefinding, correct and thorough treatment of diagnosed patients and follow-up of those in contact with TB patients, the spread of TB both in the prison and into the community can be prevented. As a part of a comprehensive programme of TB control in the central prison in Qazvin, Islamic Republic of Iran, a programme of active case-finding was carried out. This paper describes the programme and the profile of TB cases detected.

\section{Methods}

The survey was performed from 21 February 2004 to 10 July 2005 in Qazvin central prison. It was carried out with the cooperation of the health deputy of Qazvin University of Medical Sciences, the Department of Infectious Diseases of Buali Sina Hospital and the general bureau of the provincial prison.

Before the survey, the proposal, in health system research format, was approved by the research deputy of the University. The researchers coordinated with the directorgeneral of Qazvin province prisons in order to operationalize active case-finding to assess TB prevalence among prisoners.

\section{Study location}

Qazvin central prison is located in the town of Chubindar, about $5 \mathrm{~km}$ south-west of Qazvin city. The total inmate capacity is 1000-1400 prisoners. It has 7 different divisions with 6 blocks for men and 1 for women for those sentenced for financial crimes or drug crimes, and for life prisoners, young people (18-25 years), military prisoners and so on. All of these facilities enjoy sufficient ventilation and appropriate light.

The prison has an outpatient clinic to examine and treat common diseases and a health centre for high-risk diseases. It is common practice to identify TB patients through passive case-finding after routine examination of prisoners with chronic cough suspected of having TB.

\section{Case-finding}

We visited prisoners in the clinic of the prison 3 times a week during the survey period. For each prisoner we noted demographic details on a questionnaire, took a complete medical history and made a clinical examination, focusing on the chest 
and neck and axillary lymph nodes. For every prisoner who had a history of cough for more than 2 weeks (with or without fever), night sweats, anorexia, chest pain and haemoptysis, 3 sputum samples were collected ( 2 spot samples on the screening day and 1 morning sample). The samples were collected in the presence of a nurse assistant and sent to the district TB laboratory with the standard form of the Iranian national TB programme.

Smear microscopy was performed by standard methods [3]. If all 3 smears were negative, antibiotics (usually ampicillin) were then prescribed for 2 weeks and the patient was re-examined [3]. If 2 or more smears were positive, the case was diagnosed as smear-positive and DOTS (directly observed treatment, short-course)was started as soon as possible. Patients who remained suspected of TB were followed up by repeating sputum smear microscopy with 3 more samples or by other necessary examinations, e.g. sputum culture. X-ray was done in smear-positive patients before and after treatment at Avecina Hospital. Suspected TB patients were isolated in a room with appropriate light and ventilation until their smears converted to negative. They were also put on a high-protein diet. Two sputum samples were collected after 2 , 4 and 6 months of treatment for follow-up measures [3].

The patients' families were evaluated for TB and prophylaxis treatment was prescribed for children under 6 years of age, according to the World Health Organization protocol [3].

\section{Training}

During the study period, a training course with an average duration of 1.5 hours was administered to around 950 prisoners over 15 sessions, showing an educational video film on TB symptoms, transmission and prevention methods. Pamphlets were distributed among the participants of the courses. Question-and-answer sessions at the training were highly appreciated by the prisoners.

\section{Results}

A total of 768 prisoners $(95 \%$ males and $5 \%$ females) were examined. Most were aged $21-30$ years $(48.3 \%) ; 60 \%$ were married (Table 1$)$. A few prisoners (1.4\%) were non-Iranians from Iraq or Afghanistan.

Chronic cough was found in 93 (12.1\%) prisoners and 87 of these $(11.3 \%)$ had productive cough. Fever, decreased appetite, weight loss and night sweats were reported in $1.2 \%, 3.3 \%, 4.8 \%$ and $2.0 \%$ of examined prisoners respectively. A total of $78.1 \%$ were smokers, $13.9 \%$ were nonsmokers, $6.8 \%$ passive smokers and $1.2 \%$ had quit smoking. History-taking showed that $0.5 \%$ had a history of diabetes, $0.8 \%$ chronic respiratory disease such as asthma, and $0.5 \%$ had chronic renal disease.

From the 768 prisoners examined, 41 (5.3\%) were suspected of TB and gave sputum samples. From these, 7 smear-positive TB cases were found, giving a TB prevalence in the prison of $0.91 \%$; 6 of them had $3+$ positive sputum smears and 1 had 1-9 acid fast bacilli in his sputum smears. All of the 7 patients were male; 6 were aged $21-40$ years and 1 was 54 years old. Only 1 of the 7 patients was married (Table 1). All of the diagnosed cases were users of cigarettes and opium. None of the 7 patients had a history of TB or any associated disease.

Chest X-rays showed multiple cavities with extensive left lung involvement (twothirds of left lung) in 1 of the patients and reticular images in the apex of right lung were found in another. In 2 TB patients, an apparent consolidation with multiple cavi- 


\begin{tabular}{|c|c|c|c|c|}
\hline \multirow[t]{2}{*}{ Variable } & \multicolumn{2}{|c|}{ Total $(n=768)$} & \multicolumn{2}{|c|}{ TB patients $(n=7)$} \\
\hline & No. & $\%$ & No. & $\%$ \\
\hline \multicolumn{5}{|l|}{ Sex } \\
\hline Female & 35 & 5.0 & 0 & 0.0 \\
\hline Male & 733 & 95.0 & 7 & 100.0 \\
\hline \multicolumn{5}{|l|}{ Age (years) } \\
\hline $10-20$ & 56 & 7.0 & 0 & 0.0 \\
\hline $21-30$ & 371 & 48.0 & 3 & 42.9 \\
\hline $31-40$ & 206 & 26.8 & 3 & 42.9 \\
\hline $41-50$ & 98 & 12.8 & 0 & 0.0 \\
\hline $51-60$ & 23 & 3.0 & 1 & 14.3 \\
\hline $61-70$ & 3 & 0.4 & 0 & 0.0 \\
\hline Unknown & 11 & 1.4 & 0 & 0.0 \\
\hline \multicolumn{5}{|l|}{ Nationality } \\
\hline Iranian & 757 & 98.6 & 7 & 100.0 \\
\hline Non-Iranian & 11 & 1.4 & 0 & 0.0 \\
\hline \multicolumn{5}{|l|}{ Marital status } \\
\hline Married & 461 & 60.0 & 1 & 14.3 \\
\hline Single & 280 & 36.5 & 6 & 85.7 \\
\hline Unknown & 27 & 3.5 & 0 & 0.0 \\
\hline
\end{tabular}

ties in the right apical lobe was found. Some degree of apical consolidation of both lungs was found in the other patients.

From 7 diagnosed and treated patients, 4 were cured with the category 1 standard regimen, 1 case completed treatment but was released before giving the last sputum sample and was lost to follow-up, and 2 failed to complete treatment. The category 2 standard regimen was applied for the 2 treatment failure cases, which resulted in 1 of them being cured. The other prisoner, whose smear converted to negative after the 4th month, was released from prison at the end of his sentence, after which treatment default occurred.

\section{Discussion}

Prisons are one of the main sources of TB in the population. In a study performed in the former Soviet Union TB prevalence in prisons was reported to be 200 times greater than the overall prevalence in the country [2]. Another study of 386 prisoners with an average age of 17.7 years in juvenile prisons in Karachi, Pakistan, showed the TB prevalence was $3.9 \%$, which was significantly higher than the $1.1 \%$ prevalence in the general population of Pakistan [4].

A similar study in Evin and Ghasr prisons in the Islamic Republic of Iran during 1998 and 1999 indicated the prevalence of smear-positive pulmonary TB was 454.5 per 100000 in Ghasr prison and 134 per 100000 in Evin prison which were 51.6 and 25.3 times more than the national rate respectively [5]. In a separate study in Qazvin central prison in 1999, the TB prevalence was 136 per 100000 , almost 20 times the smear-positive TB prevalence in Qazvin province in the same year [6]. 
In our study, the TB prevalence in the evaluated prisoners was 910 per 100000 , which was 227 times more than the smearpositive rate and 113 times the total TB prevalence in Qazvin province in the same year. This increasing trend of TB in Qazvin central prison from 136 to 910 per 100000 in about 5 years is possibly because of the increased accuracy of active case-finding and increased predisposing factors for TB infection/reactivation in the prison such as overcrowding and contact with more contagious TB cases in prison. Since there are no physical barriers to TB spread, this rising trend is a risk for the disease spreading into the outside community. Therefore continuous training programmes are needed for both staff and prisoners, especially for newcomers, in order to learn about the clinical symptoms of TB, ways of transmission and prevention of the disease as well as regular planning for active case-finding.

We had 2 cases of treatment failure and retreatment with category $2(28.6 \%)$ regimen, which is higher than reported in nonprisoner patients $(2.9 \%)$ [7]. In both failure cases, multiple cavities were found in their chest X-rays. The difference in failure of treatment between the 2 groups may be due to noncompliance of the prisoners to treatment, multiple lung cavities, smoking and drug addiction. It has been established that there is a relationship between polluted air, associated lung disease and TB infection or activation of hidden TB [8]. Therefore efforts should be made for all prison inmates to refrain from smoking and drug abuse and for treatment to be performed under greater supervision and care.

Although chest radiography was necessary for some of the suspected TB cases, it was done only at the beginning and end of treatment because of the unavailability of radiography inside the prison and the security problems of doing it outside the prison. It is important to state that chest radiography should be a basis for TB screening in prisons where the prison population is above capacity and in areas that are hyperendemic for TB [9]. Due to the importance of chest radiography in the early diagnosis of pulmonary $\mathrm{TB}$, especially in smear-negative cases, it is hoped that chest radiography is made available for health officers in the prison for pulmonary cases (with cough more than 2-3 weeks), especially in newcomers.

\section{Acknowledgements}

We thank the Director-General of Qazvin Province Prison Bureau and the physician in charge of the prison for their cooperation, and the research deputy of Qazvin University of Medical Sciences and the staff of the tuberculosis laboratory affiliated to Shahid Bolandian, who did a marvellous job in this project.

\section{References}

1. Maher D et al. Guidelines for the control of tuberculosis in prisons. Geneva, World Health Organization, 1998 (WHO/ $\mathrm{TB} / 98.250)$.

2. Aerts A et al. Pulmonary tuberculosis in prisons of the ex-USSR state Georgia: results of a nation-wide prevalence survey among sentenced inmates. International journal of tuberculosis and lung disease, 2000, 4(12):1104-10.

3. Nasehi M, Mirhaghani L. [National guidelines for fighting against tuberculosis]. Centres of Disease Control, Ministry of Health, Islamic Republic of Iran, 2002 [in Farsi]. 
4. Shah SA et al. Prevalence of pulmonary tuberculosis in Karachi juvenile jail, Pakistan. Eastern Mediterranean health journal, 2003, 9(4):664-74.

5. Salek $S$ et al. Evaluation of tuberculosis in Evin and Ghasr prisons. Paper presented at the 5th National Congress of Tuberculosis, Shiraz, Islamic Republic of Iran, 13-15 October, 2001.

6. Asefzadeh M, Farrokhi AH. [Determining tuberculosis prevalence rate among Qazvin district prisoners.] Iranian journal of infectious diseases and tropical medicine, 2001, 15(6):58-63 [in Farsi].
7. Annual report of tuberculosis case finding and treatment results. Qazvin, Islamic Republic of Iran, Health Deputy of Qazvin University of Medical Sciences and Health Services, 2006.

8. Ruddy $\mathrm{M}$ et al. Rates of drug resistant and risk factor analysis in civilian and prison patients with tuberculosis in Samara region, Russia. Thorax, 2005, 60(2):130-5.

9. Sanchez A et al. Prevalence of pulmonary tuberculosis and comparative evaluation of screening strategies in a Brazilian prison. International journal of tuberculosis and lung disease, 2005, 9(6):633-9.

\section{Consultation on antiretroviral therapy for HIV prevention}

WHO will host a consultation on antiretroviral therapy (ART) for HIV prevention in May 2009. This meeting follows the recent publication in The Lancet of a mathematical model on ART for prevention developed by WHO scientists.

The meeting will bring together a broad range of stakeholders: researchers, health economists, modellers, policy and programme planners, civil society representatives, people living with HIV, gender advocates, human right experts and ethicists, cosponsors of UMAIDS, donors and bilateral agencies. The aim of the consultation is to discuss broad issues around the concept of ART for HIV prevention, including feasibility and acceptability, human rights and ethical implications, and research priorities.

This is an invitation-only meeting. WHO will circulate a report after the consultation, with an overview of key discussions and outputs. 